\title{
Projecting climate changes and ecological responses
}

Keywords: Climate changes, Ecological responses, Fish resources, Fishing culture, Meteorology, Weather, Fisheries, Stock assessment, Benguela, Ecological events, Climate, LOD, Climatologists, Sharp

Abbreviations: AFS, American Fisheries Society; ALPI, Aleutian Atmospheric Pressure Index; LOD, Length Of Day; PACLIM, Pacific Climate Conference

\section{Opinion}

Climate change has long been known and documented in many locations as being responsible for major ecological responses in regional ocean ecosystems. I (Sharp) was introduced to some of the 'olde fishing culture' topics by several colleagues, including the Director of FAO Fisheries Department, Armin Lindquist, who we asked to open our discussion on the subject in the 1983 Expert Consultation to Examine the Changes in Abundance and Species Composition of Neritic Fish Resources, San Jose, Costa Rica. ${ }^{1}$ Research programs that were designed to understand these complex interactions on relevant scales have been rare, although a goal for many scientists since the late 1800 s, reviewed by Julia Lajus a Russian Social Scientistat the July 2004 convergence by the International Commission on History of Meteorology under the title "From Beaufort to Bjerknes and Beyond: Critical Perspectives on the History of Meteorology". Lajus' article "Influence of weather and climate on fisheries: overview of emergence, approval and perception of the idea, 1850 1950s" can be downloaded from the following link: $<$ http://www.meteohistory.org/2004polling_preprints/docs/abstracts/ lajus_abstract.pdf>

The article begins with this: "Fishermen have long known that fisheries appear and disappear in time. Such events were attributed to changes in fish migration routes, harmful growth in numbers of natural predators of fish and to the human impact: overfishing and water pollution. ${ }^{2}$ To note that weather, especially the changes in wind direction, could influence fisheries, was easier than to suppose that large periods of fish abundance could be connected with the fluctuation of climate. For example, Karl Ernst von Baer, famous German zoologist, who worked in Russia and in addition to many diverse activities was a head of several expeditions which surveyed the state of fisheries in 1850 s, explained the severe decline of herring fisheries during several years in the eastern part of the Baltic Sea was caused by very cold and windy springs occurred these years. He supposed that the winds pushed out the spawning herring from their usual spawning grounds ${ }^{3}$ But at the same time he did not apply this kind of argumentation when he discussed the possible causes for the cessation of the very prosperous herring fisheries in Bohuslan region on the western coast of Sweden in the beginning of the 19th Century. He supposed instead that it was the human induces pollution due to fish oil production. For the first time the climatic explanation for the periodicity of these fisheries was suggested by Axel Ljungman in Sweden. ${ }^{4}$ He noted that the herring catches varied cyclically with a period of the fifty year sunspot cycle and assumed that this relationship might be explained with changes in the weather. However, he was not able to propose the mechanism for that connection. And after the summarizing book

\author{
Volume 3 Issue I - 2015
}

\author{
Gary D Sharp \\ Department of Center for Climate/Ocean Resources Study, \\ USA \\ Correspondence: Gary D Sharp, Department of Center for \\ Climate/Ocean Resources Study, 780 Harrison Road, Salinas, \\ California, 93907, USA, Email gsharp@redshift.com
}

Received: October 20, 2015 | Published: November 5, 2015

by Cushing. ${ }^{5}$ the notion that climate change could influence the fish resources and therefore fisheries, became commonplace. But the question is still very important and new facts and correlations are discussed by fishery scientists in cooperation with climatologists.

The real issue is whether there is a direct causal link, or these are merely correlated consequences of larger scale processes." It has been Sharp's goal for decades, to bring local knowledge, expertise based on empirical observations into the resolution of the cause and effect issues and he has been fortunate to have begun his queries while these issues were being actively investigated in the laboratory and at sea by the Reuben Lasker, John Hunter, Elbert Ahlstrom and Paul Smith team at the La Jolla BCF/NOAANMFS Fisheries Research Laboratory, where the root stock of these basic approaches had been imported by Lasker from the Fisheries Research Services Marine Laboratory situated in Aberdeen, Scotland. As Jorge Csirke and Sharp concluded after their review . ${ }^{6}$ and report of the Changes in Abundance and Species' Composition of Neritic Fish Resources, fisheries, stock assessment would be in a very different state if the North Sea were subject to El Niño events. Recent decades have been the heyday for the near miss regression/correlation approach to modeling environmental effects on resources populations. At the 2000 IFFET gathering in Portland, Oregon, Sharp provided a "Brief Review of the History of Fisheries Science and its Relation to Fish Culture" http://oregonstate.edu/dept/ IIFET/2000/abstracts/sharp2.html

That presentation outlines the important role of "studies done in the mid 1800 s by Norwegian fisheries biologists and laboratory scientists (that) created the first controlled scientific environments for studying the early life history stages, rearing and release programs in support of ocean fisheries enhancement. By the end of the 19th Century methods and concepts were transferred to Canada and the USA, to become the basis of North American fisheries science." In Sharp. ${ }^{7}$ the chapter entitled "Tuna Oceanography An Applied Science" was published in Tuna: Physiology, Ecology \& Evolution, edited by Barbara Block and Don Stevens linking all of these developments in time.

Mean while, back in 1987 Sharp wrote an essay on request from John Hunter, editor of the AFS (American Fisheries Society) Monthly "Averaging the Way to Inadequate Information in a Varying World" in response to the Benguela 86 Symposium where one of the participants decided to make a very strange recantation of the scientific method. 
There was sufficient evidence, in his view, to suggest that there was no reason to do the causal research in fisheries related marine ecology, once the conventional average fishery information or parameter estimates were available. You could be right more often using average expectations in your data than if you used any three random variables with combined explanatory capabilities of up to $75 \%$. He then proceeded to exemplify his conclusions from his analyses. This statement came as a surprise and disappointment as it came from an exceptionally talented mathematical analyst. Perhaps doubly so, since among the several dozen other presentations at this symposium there were also very memorable contributions that evidenced the value of understanding the causal sequences of climatic to, oceanographic, to ecological events and patterns, that characterize the dynamic Benguela Current Ecosystem, in particular its periodic reversion from one quasistable state to another. ${ }^{8}$ Once stated, such a position will make it more difficult to induce such "enlightened" folk to recognize the logical errors that lead to these wrong conclusions. Shannon et al. ${ }^{9}$ summarized nicely what had taken place over the previous decade and expanded the region's approach to System Science, as Fisheries Science should eventually evolve to become. After a few more years of intensive in situ sampling Verheye ${ }^{10}$ provided a reasonable historical review for the Benguela Current System that warranted more attention than it received that confirmed the value of empirically based science.

While Ocean Fisheries Ecosystem Modeling has become an academic field of general interest, the empirical observations necessary to build and implement effective models are rarely available, creating many examples of unreliable and unverified model results that too often simply do not represent anything of real utility. E.G., Models that don't reflect environmental contextual changes, directly, such as changes in thermal habitats, as well as wind and cloud cover related production patterns and direct species responses to well described known forces, other than simplistic Top Down driven trophic energy transfers, cannot reliably provide the needed insights necessary to either explain past changes, or project potential future changes. There is a subtle philosophical twist attendant to the failure of these partial models to forecast ad infinitum the patterns of any population's responses to regimes outside the models' basis, or too often too short reference period. There is no reason to expect that the low level population dynamics modeling that we have accomplished could forecast any but past responses. That is if the signals were strong enough to make projections from. Yet, these generic models assume average responses without querying the potential for any other dominant variables to emerge.

And, then, of course, in retrospect, we think that any argument for use of simple averages is a strong signal that it is about time for such analysts to be removed to the back seat, or somewhere that will minimize data fatigue. In fisheries science, the most important relevant realization that needs to be made is the following: "The Average Fish Dies with in its First Week of Life!"

Where does this leave our average mathematician? With myriad surviving, not so average fish. In fact the average conditions of the ocean will not support most fish life at all. Therefore, there must be some alternative way to organize the science if we are ever to reach the objective of forecasting even the less subtle aspects of marine populations such as changes in relative abundance or their distributions. We think that the solution is for fisheries researchers to go back to the basic questions of elementary biology. What mechanisms do the various populations have and at what developmental stages, that allow them to survive local environmental perturbations? What are the conditions to which these individuals are adapted and finally, what perturbs these conditions in time and space and what options are available for the generations involved? Unfortunately, due to reluctance by many agency policy makers to fund the necessary monitoring of both physical and ecological components and the dominant presumption that underlying all ecology there are fundamental equilibrium processes that determine the System State surprises keep occurring. Within the recent decades there have been many gross simplifications and analyses of particularly undependable data sets from too short time series of species landed catch data, various local temperature series and some in situ sampling of plankton, etc. and thus the potential for any dependable projections have been minimal and mostly quite gloomy. However, in the $1960-90$ period when biological oceanography was the basis for many powerful efforts to understand the fundamental requirements for successful year class production in many ocean species, it became obvious that wind speed and direction, incident sunlight and temperature were the fundamental processes that determine which species would thrive and by tracking these and the subsequent production patterns, useful forecasts of likely species specific survival changes could be made.

Emanating from this cascade of physical and biological signals are the unique experiences of surviving individuals, not the deadly averages. All long known, as per Sharp's Chapter in the 1981 ICES Report, "Colonization in Fishes Some Inferences Concerning Requirements and Opportunism in the Sea" in which he brings together the basic concept that was a result of a decade or so of research by the fisheries laboratory staff in La Jolla, that showed that "the egg to larval transformation period" is the greatest potential "bottleneck" period for a fish population, then one can also conclude that the complexities of the following life stages represent an evolutionarily successful egg's way of getting itself reproduced and deposited in an appropriate environment. Also included were insights from a review of FAO Annual Catch Statistics provided the trajectories of catch trends from 1970 and 1977 (Table 1). Plus and minus signs on the right in Table 1 represent directions of trends during the reference period. Changes in both directions in the order indicated.

The indication - + implies sharp changes in both directions, in the order indicated.

Twenty years later I encountered the works of Leonid Klyashtorin .$^{11,12}$ and had him introduced to colleagues at FAO Fisheries Department in Rome. Klyashtorin was invited to come and present his work and then asked to write a Technical Report for which I (Sharp) was asked to do the final English editing for publication, Klyashtorin. ${ }^{13}$ " Climate change and long term fluctuations of commercial catches: the possibility of forecasting. FAO Fisheries Technical Report No.410, 98pp. FAO of the United Nations, Rome. Available online via this link: < http://www.fao.org/DOCREP/005/Y2787E/y2787e01.htm>

Sharp followed up on this work and with contributions in collaboration with Joseph Fletcher and Douglas Hoyt (both strong proponents for Solar influences on the ongoing climate changes,) and others, generating another technical report "Future climate change and regional fisheries: a collaborative analysis" in which you can read Sharp's views on the consequences of future climate change on regional fisheries around the globe available from FAO Library via this link: ftp://ftp.fao.org/docrep/fao/006/y5028e/y5028e00.pdf

Given these insights and the long term insights from old cultures about Atmospheric Cycles and consequent species dynamics, it is now possible to focus on when and where to monitor various properties that will enhance the benefits of both System Monitoring and Resource Management. We provide examples for future reference. 
In February 2006, at the ASLO/AGU/CLIOTOP meetings in Hawaii, Sharp presented a lecture entitled "A Brief History of Applied Fisheries Oceanography Part II. The Role of CLIOTOP and TOPP in Revitalizing Ocean Sciences". In Short: "Underlying the basic responsibilities of resource management are very important questions requiring careful study and long term monitoring efforts in order to validate and upgrade conventional management methodologies."

Table I Trajectories of catch trends between 1970 and 1977

\begin{tabular}{|c|c|c|c|c|c|}
\hline Species & Area & Peak Catch & Low Catch & Ratio A/B & \\
\hline Caranx Hippos & West Africa & 28221 & 1036 & 27 & + \\
\hline Orcynopsis Unicolor & West Africa & 2600 & 100 & 26 & -- \\
\hline Trachurus Capensis & Southwest Africa & 690164 & 62300 & 11 & + \\
\hline Trichiurus Lepturus & Southwest Africa & 28545 & 3800 & 7.5 & + \\
\hline Trachurus Trecae & Southwest Africa & 273700 & 31298 & 8.7 & -- \\
\hline Sardinella Spp. & Southwest Africa & 142200 & 20986 & 6.8 & --+ \\
\hline Scomber Japonicus & Peru & 65000 & 8700 & 7.5 & + \\
\hline Scomber Japonicus & Northeast Atlantic & 39000 & 6262 & 6.2 & -- \\
\hline Rastrelliger Spp. & Eastern Indian Ocean & 16300 & 2000 & 9.2 & + \\
\hline Rastrelliger Kanagurta & Eastern Indian Ocean & 203100 & 35403 & 5.7 & -- \\
\hline Anchovies & Western Indian Ocean & 118062 & 16900 & 7 & + \\
\hline Psenopsis Anomala & Northwest Pacific Ocean & 13000 & I 994 & 7 & -- \\
\hline Sardinops Melanosticta & NW Pacific Ocean & 1420512 & 16900 & 84 & \\
\hline Engraulis Mordax & Eastern Pacific Ocean & 289002 & 44600 & 6.4 & + \\
\hline Cetengraulis Mysticetes & East Tropical Pacific & $|6808|$ & $1555 \mid$ & 10.8 & + \\
\hline Trachurus Symmetricus & Eastern Pacific Ocean & 50149 & 9400 & 5.3 & + \\
\hline Sarda Chiliensis & Southeast Pacific Ocean & 74700 & 4341 & 17.2 & -- \\
\hline Scomberomorus Sierra & Peru & 2279 & 400 & 5.7 & + \\
\hline Engraulis Ringens & Peru & 13059900 & 907175 & 16 & -- \\
\hline Sardinops Sagax & Peru-Chile & | 467555 & 68600 & 21 & + \\
\hline Trachurus Trachurus & Peru-Chile & 839805 & 111300 & 7.6 & + \\
\hline Thyrsitops Lapidopodes & Chile & 7200 & 630 & 11.6 & -- \\
\hline Cetengraulis Edentulous & Venezuela & 4965 & 850 & 5.8 & --+ \\
\hline Decapterus Russelli & Malaysia-Thailand & 109337 & 9800 & 11.2 & + \\
\hline St Scomberoides Spp. & Indonesia-Philippines & 5186 & 500 & 10 & + \\
\hline
\end{tabular}

Hence the many collaborative efforts to bring these longer and more insightful empirical and theoretical investigations into our local domain and our continuing efforts to help our own deeper delving researchers integrate their findings with those of these more complex, broader approaches to the many ecological and social issues. Fisheries management should include understanding tessellations of causal physical climatic oceanic processes, near and remote, that initiates ecological perturbations, along with the careful analysis of man's harvests and consequent ecological responses. These subtle generation to generation responses to environmental trends and anomalies selects for either geographic flexibility, as observed in the nomadic opportunists or numerical swarming as observed in the clupeids (anchovy) and engraulids (sardines), which is restricted, for success, to areas of relative year to year stability. The rise and fall of these localized populations is probably more characteristic and dramatic than the year to year biomass or number variations in the opportunistic nomadic forms. The examples in Table 1 provide the relative catch variations in 25 local or regional pelagic fisheries from the years 1970 to 1977 . All these examples varied by more than plus or minus $5 \mathrm{X}$ during this eight year period. This is why we need to be careful when modern computer based studies use percentage change criteria as their basis for doom and gloom scenarios. ${ }^{14}$ As if no oceanic fisheries exhibited this level of apparent abundance variation within short periods, apart from a few cases where political or economic factors other than basic resource abundance, rather than changing markets or environmentally determined vulnerability (or availability) have affected the total landings.
In 2001, Klyashtorin ${ }^{13}$ was invited as Visiting Scientist at NOAA NMFS Pacific Fisheries Environmental Laboratory in Monterey Bay and he arrived in time to participate in that year's Pacific Climate Conference $=$ PACLIM Conference. After we were able to talk one-onone and Sharp had introduced him to many of the region's climate and fisheries experts, they began discussions of how to get the Old Russian climate science brought into western scientist's attention, to help bring western science forward. On his return to Russia, Klyashtorin wrote many new papers with several of his mathematically gifted colleagues and gave presentations at several meetings. In 2005, Klyashtorin \& Lyubushin $^{15} 234$ page book on "Cyclic Climate Changes and Fish Productivity" was published. In Russian providing a long overdue reintroduction to the means for coping with the comings and goings of major fisheries populations. Among some hundred graphics, the following three provide useful hints about where we should all be heading by looking forward based on Historical Information (Figure $1-3)$.

Another example of what is useful about enhancement of fundamental catch information about fish landings with more broad scale phenomena is found in the Figure 4, where Klyashtorin and Lyubushin have overlain the temperature reconstructions from Greenland ice cores and the Global Temperature anomaly on the historical records of Japanese sardine fisheries activities. To which Sharp added the colorized Warming vs cooling trends to show that sardine populations appear to thrive whenever the trend is positive and rapidly shut down when the warming trend stops and cooling ensues. 


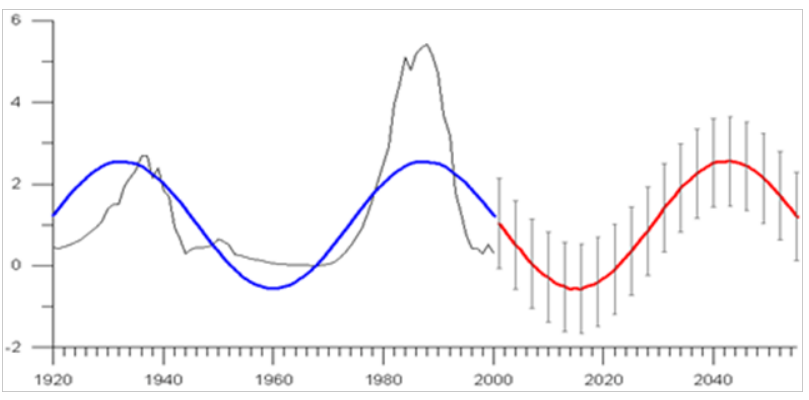

Figure I The projected trend of total commercial catches (million. tons; bold line) of Japanese sardine Sardinops melanosticus with a 50 year future perspective. Thin line shows commercial catch; bold red line shows probable trend marked with uncertainty via the vertical bars.

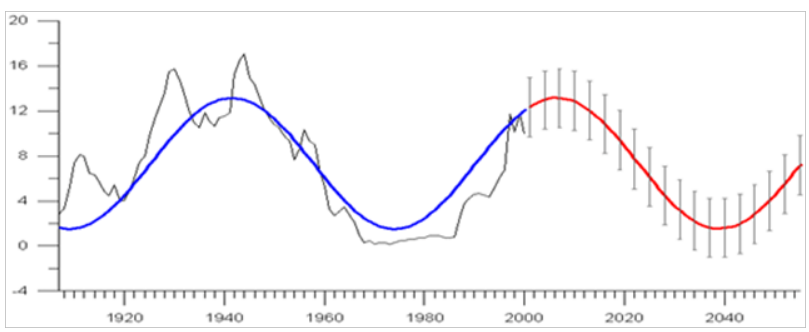

Figure 2 The projected trend of total commercial catches (100 000 tons; bold line) of Norwegian spring-spawning herring for the next 50 years. Thin line shows commercial catch; bold red line shows probable trend marked with potential uncertainty via vertical bars.

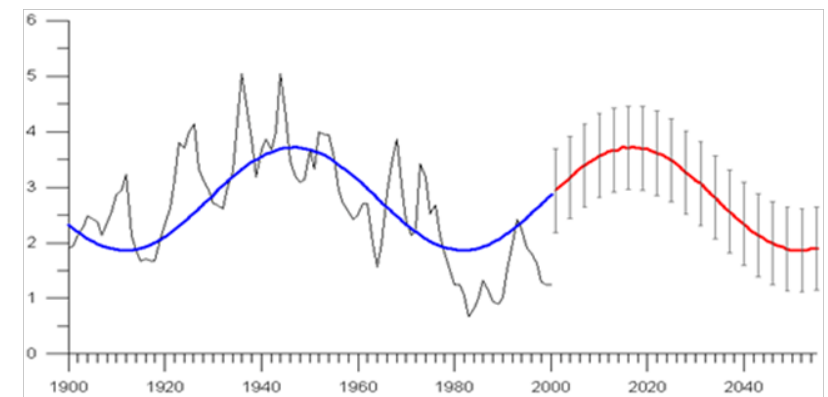

Figure 3 The projected trend of total commercial catches (million tons; bold line) of Norwegian Arctic cod Gadus morhua for the next 50 years. Thin line shows commercial catch; bold red line shows probable trend marked with uncertainty via vertical bars. (They are indeed re-establishing their old habitat in the Baltic Sea - today.)
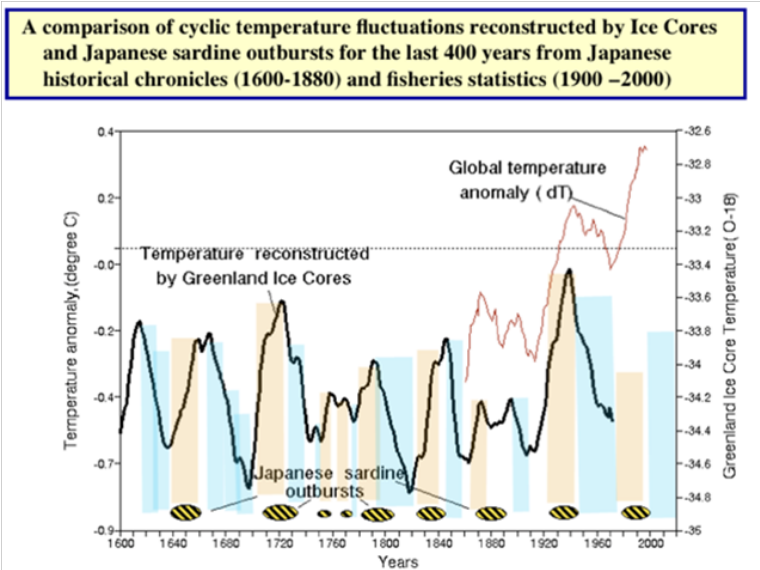

Figure 4 Kawasaki's Japanese sardine fishery historical records with Ice Core and Global DT-when it warms the sardine bloom, and cooling induces collapses.
Master fisherman and multilingual Menakhem BenYami wrote for the renown bimonthly newspaper World Fishing, Dec. 2006/Jan. 2007, an article entitled Enlightment From Russia a review of the 2005 (in Russian) Klyashtorin \& Lyubushin ${ }^{15,16}$ book "Cycic Climate Change and Fish Productivity "A wise man said once: a people without history is a people without future. [We] paraphrase: science that ignores former studies and historical data cannot produce reliable predictions. This is also true for all those who attribute to fishing being the single or predominant cause for all trends and variations in fish populations."

[We all wonder how useful articles are that are] "Based on references quoted in so many learned articles on fisheries related subjects that reach only 5 or 10 year back. Fisheries Science started developing in the mid $1800 \mathrm{~s}$, with a strong ascent in the early decades of the last century and has flourished since. Long term data series and historical information on fish yields fluctuations and on climatic variations, as well as biological/ecological knowledge on life history and behaviour of the main commercial species have been long available..." And the Review finishes with: "One can only conclude that ignoring regime shifts and other climatic fluctuations can lead to misunderstanding of the role of fishing on marine fish populations and their ecosystems and consequently to their mismanagement. While overfishing is a fact in many cases, it alone doesn't explain the boom and bust fishing reality. Neither can management steps "recover" fish stocks to their former state, if those are on a downward section of their natural cycle." Klyastorin \& Lyubushin ${ }^{16}$ also show that there is a very positive relation between these and many other ocean indices such as the PDO, ACI, Aleutian Atmospheric Pressure Index (ALPI) Arctic dT, etc, with the changes in the earth's rotation rate or more specifically the negative Length of Day (LOD). Their other exciting finding was that the changes in the LOD actually precede the changes in the other indices providing a useful signal that helps to focus attention on what to monitor where and when providing more useful information on both the environment and the resource responses. To make this information accessible to all, their book was recently translated into English and Sharp was asked, again, to do the English editing of the translation, finalized in March 2007. The English version of book is now available online free:

http://narod.yandex.ru/100.xhtml?alexeylyubushin.narod.ru/ Climate_Changes_and_Fish_Productivity.pdf

More About Uncertainty, we know for certain only two things. The first is a matter of history rather more than science: namely, that since about 1860, when accurate temperature records were first collected on a comprehensive basis, northern hemisphere temperatures have risen by about $0.6^{\circ} \mathrm{C}$; and that this coincides with a steady growth in the amount of carbon dioxide in the atmosphere, a proportion of which is a consequence of industrial and other manmade emissions. The second is that our planet is kept from being too cold for life as we know it to survive by the so called greenhouse effect, which traps some of the heat from the sun's rays. This is overwhelmingly somewhere between 75 and 95 per cent caused by clouds and other forms of water vapor; and the carbon dioxide in the atmosphere accounts for much of the remainder. But so great is the uncertainty of climate science that it is impossible to say and it is hotly disputed how much of the modest warming that has been experienced since 1860 is due to the manmade increase in carbon dioxide.

We also have some opinions that $\mathrm{CO} 2$ levels and Humanity are related. However, it is poorly recognized is that Global Warming since the Little Ice Age period of extreme low temperatures promoted the growth of both human population and $\mathrm{CO} 2$ levels as will be shown. During the period since 1860 , for which we have accurate temperature 
records, the picture is complicated. While the amount of manmade carbon dioxide in the atmosphere has, since the industrial revolution, more or less steadily increased, the corresponding temperature record is more cyclical, displaying four distinct phases: 1) Between 1860 and 1915 there was virtually no change in northern hemisphere temperatures; 2) between 1915 and 1945 there was a rise of about 0.4 ${ }^{\circ} \mathrm{C}$; 3) Between 1945 and 1965 the temperature fell by about $0.2{ }^{\circ} \mathrm{C}$ and alarmist articles by various folks began to appear, warning about the prospect of a new ice age and 4) between 1965 and 2000 there was a further increase of about $0.4{ }^{\circ} \mathrm{C}$, thus arriving at the overall increase of $0.6{ }^{\circ} \mathrm{C}$ over the 20th century. Although, so far this century, there has been nothing to match the high temperature recorded in 1998, it would be rash to assume that this latest upward phase has ended. We know, however, that $\mathrm{CO} 2$ will continue to rise as human activities and their survival in general are still growing: However the human $\mathrm{CO} 2$ emissions remain a rather small component within the Global $\mathrm{CO} 2$ Cycle (Figures 5).

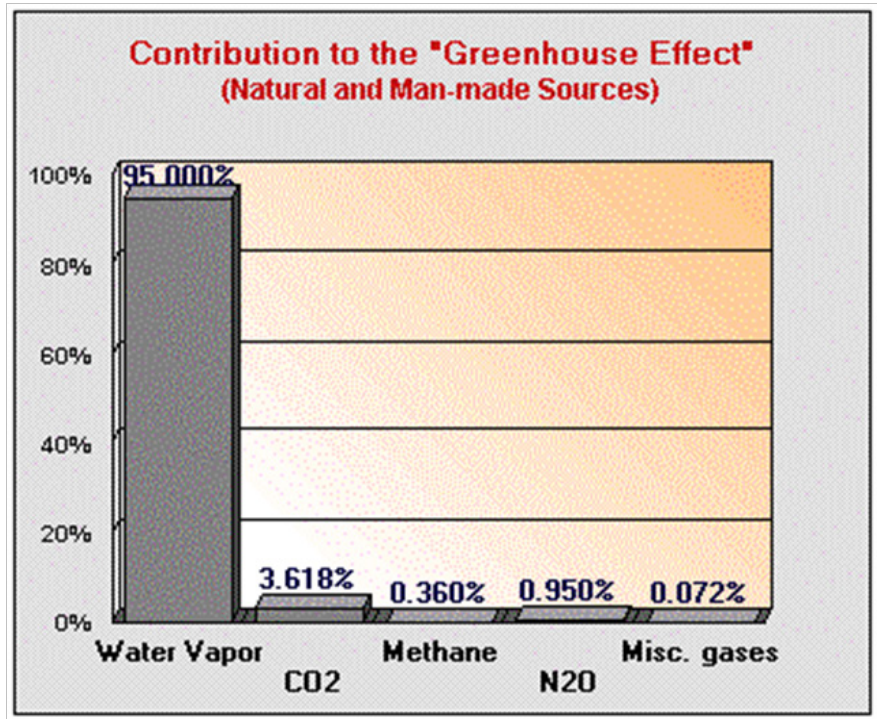

Figure 5a Major atmospheric Greenhouse Warming components.

\section{Carbon Dioxide (CO2)}

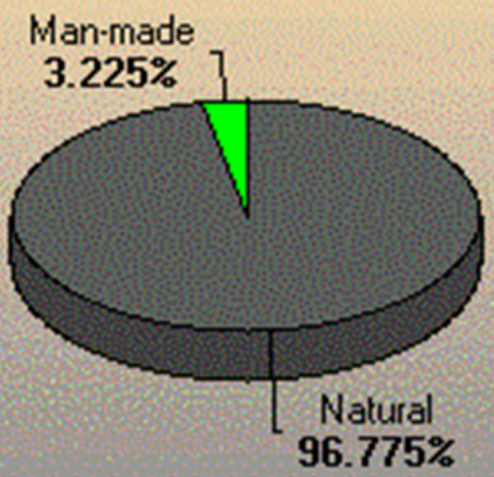

Figure 5b Proportion of Atmospheric $\mathrm{CO}_{2}$ of Total that is man-made.

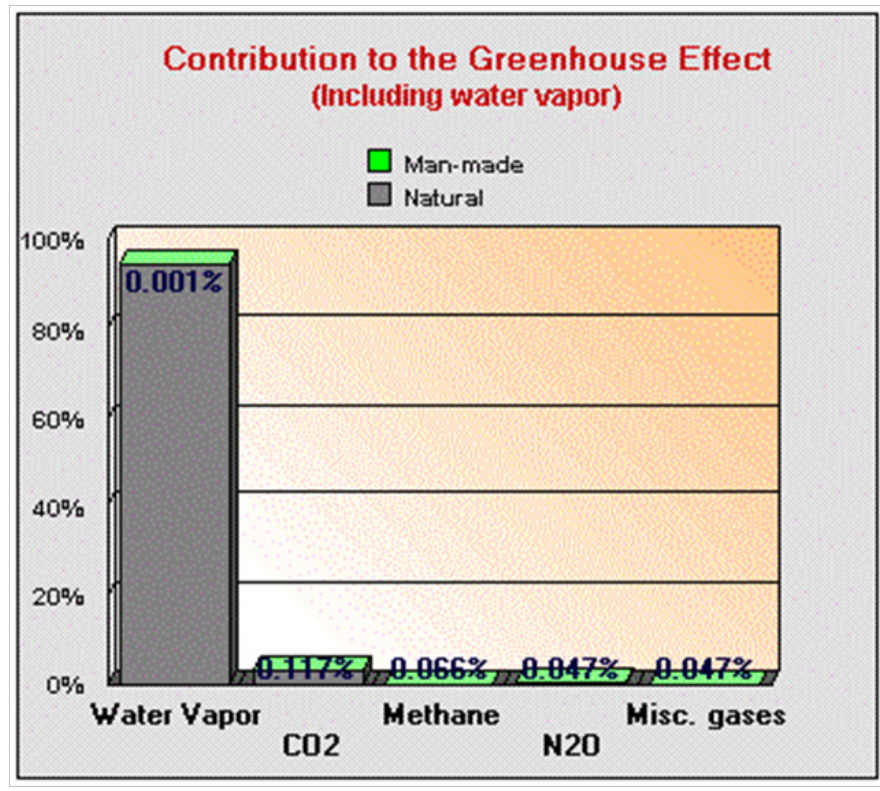

Figure 5c Total Human contribution to Green House effect $=\sim 0.278 \%-$ not very great portion.

Needless to say, these confusing issues are likely to enhance future problems, if not dealt with correctly and the more appropriate empirically based science rather than continued over parameterized modeling. In my own rather complex field of Applied Fisheries Oceanography we have suffered a rather odd parallelism with Climate Change Science as computer modeling has taken over empirical observation based approaches to forecasts and has resulted in many poor management decisions. What is also not obvious to the public, given the various efforts by various interests to distort the real world needs for empirical observations and monitoring of all important Resource Systems, is that the losses of funding for these activities over the recent two decades has led to a state of uncertainty on all time and space scales that cannot be dealt with using satellite technologies alone, nor from meritless over parameterized or 'guesstimate based' modeling using 'mean expectations' from short observation series. ${ }^{17}$ The consequences of such losses were all too obvious when we recently set about updating our work on the importance of in situ time series data and relevant indicator species behavior changes, to discover that for many ecologically important coastal regions around the globe, the numbers of records and area coverage had declined dramatically.

Sharp introduced Douglas McLain to Barbara Block and both suggested that the ongoing expansion of archival tagging of ocean pelagic species provided real world observations offering a real solution to this problem, if these programs' instrumental data were to be entered into the global ocean data bases. Amongst the most promising of the ongoing efforts has been the CoML/TOPP Tagging of Pacific Pelagic species, outfitted with sensors and satellite tracking/ information transfer gear (Figure 6). TheCoML/TOPP websites offers a full description of what has been learned and where the future efforts will be focused:

\section{$<$ http://www.coml.org/descrip/topp.htm>}

From the tables summarizing the sample numbers by various TOPP tagged species and the very broadly distributed but relatively 
expensive and slow moving ARGOS floats it is obvious that there are distinct benefits arising from the animal tagging efforts (Figure 6), in sheer numbers of observations and well as insights into what features the various species respond to. All very important information for resource management decision making. Clearly, there is a general need for more empirically based, informed resource management efforts, rather than the outmoded and clearly unsuccessful equilibrium based population modeling that underlies the recent decade's management failures. Over the recent year or so, some of the needed improvements have been ongoing and we expect major improvements in global ocean data access and considerable regional contributions as the TOPP and related animal based instrumental data sets are entered into the global data base Figure 7. This diagram was provided by Walli, ${ }^{18}$ who worked within the Hopkins Marine Station Tuna Research Laboratory while earning his PhD at UC Santa Cruz under the guidance of both Dan Costa and Barbara Block. His thesis was a three part visual summary of the decade of satellite tagging of Atlantic bluefin tuna and what was learned. Their migration patterns shift within various stages of their life histories in response to the multiple environmental variables that influences their behavior, from locations of forage regimes, onward to first spawning and beyond. These findings simply defy the present greed based biase approaches used in the management of eastern Atlantic and Mediterranean bluefin tuna fisheries. If we are indeed to ever become empowered with forward looking techniques and technologies, it will only come from acknowledgement of the integrated nature of these complex problems and a serious investment and recuperation of our global monitoring capabilities.

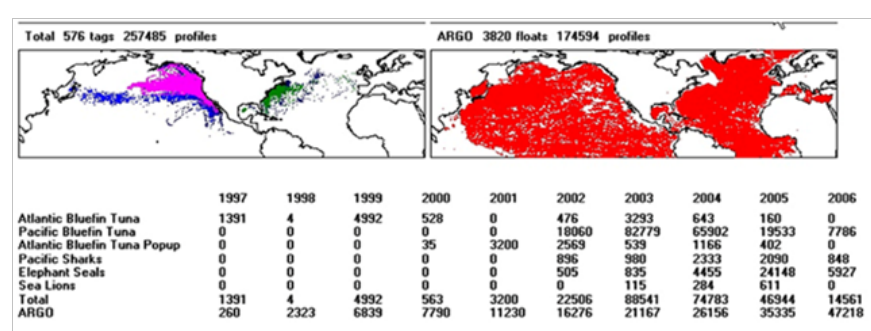

Figure 6 Provides some interesting insights.

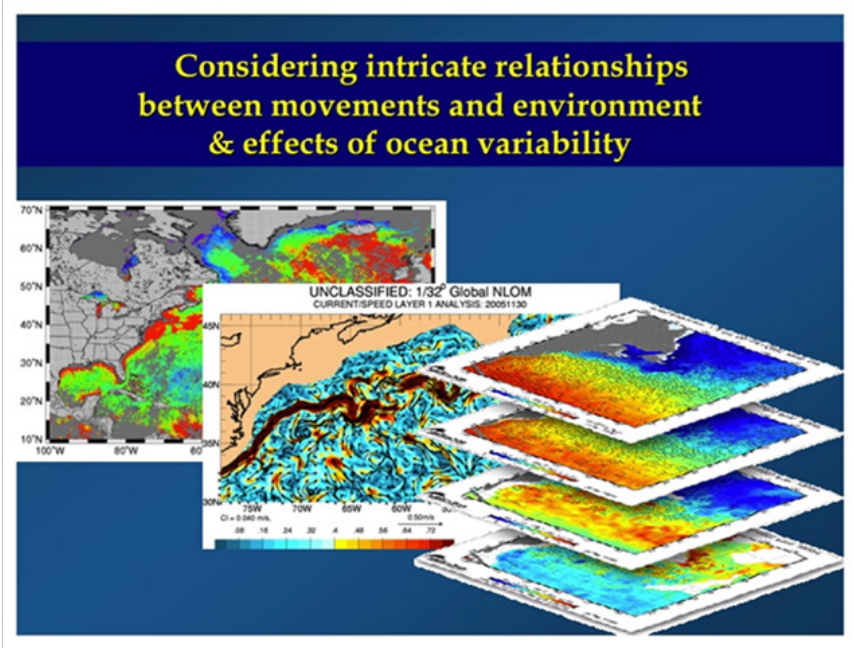

Figure 7 Considering intricate relationships b/w movements and environment \& Effects of ocean variability.

\section{Conclusion}

Klyashtorin \& Lyubushin ${ }^{15,16,19}$ represents the most authoritative and upto date analysis of the historical effects of climatic and planetary factors on fishery resources, in particular and fishery ecosystems, in general. It will, hopefully, open the eyes of fishery scientists and managers to the bitter truth that they cannot "recover" a stock that is on the downward slope of its multiannual variation. Neither should they repress a fish stock that's less than half way up on the upwards slope of its cycle by allowing overdevelopment of fishing effort, or once the stock is in decline continued fishing. Hopefully, the book's many messages will help in long overdue overhauling of the prevailing fisheries science cum management system. What emerges that we and others have long urged are some obvious things to do now in order to resolve the important resource management issues:

a. What's coming up? Monitor Climate Indices and LOD

b. Which Species will do what given historical response information

c. Define Indicators of Transitions both Physical and Ecological

d. Continuous Catch Monitoring via Collaborations with Fishermen

e. Rapid Control/Management of Fishing Effort Location and Intensity

f. Continuous Environmental Monitoring for Long Term Signals

g. Rapid Response to Event Scale 'Noise' i.e., ENSO Warm/Cold

h. Market Floor Flow Through Measures to Inhibit Gold Rushes

i. Reeducation of Fisheries Managers and Industry about Transitions

j. Coping With Change Is What Life Is All About Per Sharp's Historical Summary at $<\mathrm{http}$ ://www.johndaly.com/sharp.htm>

And, as we typically finalize our continuing communications looking forward!

\section{Acknowledgements}

I have worked hard and long with both LEONID KLYASHTORIN (VNIRO, Moscow $=$ now deceased) and DOUGLAS McLAIN (CoML/TOPP, Pacific Grove, CA) and their contributions are fundamental to my having been able to write and provide data and graphics of this article.

\section{Conflicts of interest}

None.

\section{References}

1. Lindquist A Herring and sprat: fishery independent variations in abundance. In: Sharp \& Csirke (Eds.), FAO Fish Rep Ser. 1983;291(23):813-822.

2. Smith TD Scaling Fisheries: the science of measuring the effect of fishing, 1855-1955. Fisheries Oceanography. 1994;4(2):191-192.

3. Baer von KE Rybolovstvo v Chudskom i Pskovskom ozerakh i v Baltiiskom more [Fisheries in the Chudskoe and Pskovskoe lakes and in the Baltic Sea]. Issledovaniia rybolovstva v Rossii, St. Petersburg. 1860

4. Ljungman A Contribution towards solving the question of the secular periodicity of the great herring fisheries. US Comm. Fish Fisheries. 1882;7(7):497-503.

5. Cushing DH Climate and Fisheries. Academic Press, London, pp. 1982;373.

6. Csirke J, Sharp GD Reports of the Expert Consultation to Examine the Changes in Abundance and Species Composition of Neritic Fish Resources, San Jose, Costa Rica, pp. 1984;102. 
7. Gary Sharp Tuna Oceanography: an applied science. The Ecophysiology of Tunas. In: Block B \& Stevens ED (Eds.), Academic Press, San Diego, California, USA. 2000 b

8. Sharp GS Climate and Fisheries: cause and effect or managing the long and short of it all. South Afr J Mar Sci. 1987;5(1):811-838.

9. Shannon V, Crawford RJM, Pollock DE, et al. The 1980s-a decade of change in the Benguela ecosystem. South Afr JMar Sci. 1992;12(1):271296.

10. Verheye Hans M Decadal-scale Trends Across Several Marine Trophic Levels in the Southern Benguela Upwelling System off South Africa. J Human Environment. 2000;29(1):30-34.

11. Klyashtorin LB Global climate cycles and pelagic fish stock fluctuations in the Pacific. In: Hancock et al. (Eds.), Proceedings of Second World Fisheries Congress. CSIRO, Australia, p. 1997;24.

12. Klyashtorin LB Long-term climate change and main commercial fish production in the Atlantic and Pacific. Fisheries Res. 1998;37(1-3):115125 .
13. Klyashtorin LB Climate change and long term fluctuations of commercial catches: the possibility of forecasting. FAO Fisheries Technical Paper 410, pp. 2001;98.

14. Worm B, Barbier EB, Beaumont N, et al. Impacts of biodiversity loss on ocean ecosystem services. Science. 2006;314(5800):787-790.

15. Klyashtorin LB, Lyubushin A Cyclic Climate Changes and Fish Productivity. VNIRO Publishing, Moscow, Russia, pp. 2005;223.

16. Klyashtorin LB, Lyubushin A Cyclic Climate Changes and Fish Productivity. VNIRO Publishing, Moscow, Russia. 2007

17. Sharp GD, Klyashtorin LB, Taylor G Climate and Fisheries: Forecasting Contextual Changes, Instead of Hindcasting from Meaningless Means. Amer Fisher Soc Symp. 2008;49 997-1016.

18. Walli Andreas On the movements, aggregations and the foraging habitat of bluefin tuna (Thunnus thynnus \& T. orientalis). PhD Thesis, University of California, Santa Cruz, USA, pp. 2007;247.

19. Lyubushin A, Klyashtorin L Short Term Global DT Prediction Using (60-70) Years Periodicity. Energy and Environment. 2012;23(1):75. 